\title{
The Five Stage Cycle Model: An Online Integrated Approach to Teaching Physics
}

\author{
Maher Al-arfaj \\ College of Education, King Faisal University \\ PO box 400, Hofuf 31982, Saudi Arabia \\ Tel: 0096-635-801-786Ｅ-mail: malarfaj@kfu.edu.sa
}

Received: February 21, 2011 Accepted: February 28, 2011 doi:10.5539/ies.v4n3p166

\begin{abstract}
The five stage cycle model is an interactive flash platform that proposes a challenging scenario with associated questions about light wave features and correlations. As the students navigate from stage to stage, they are able to access some related resources and engage in small group discussions. The students are able to revisit their responses and revise them as they move from one stage to the next. Results from this study reveal that the five stage cycle, designed as a computer-based tutorial, can facilitate students' learning of physics; however, most students cannot construct a useful knowledge structure to overcome the challenging scenario they encounter.
\end{abstract}

Keywords: Cycle, Model, Teaching, Physics

\section{Research Problem}

Scientific literature shows that students always have deficits in scientific understanding. In physics, it has been reported that students at all study levels have insufficient physics comprehension skills and contradictory cognitive images for different physics concepts (Redish ,Saul \& Steinberg, 1998 ;Hammer, 1994 ;May \& Etkina, 2002 ; Malkawi \& Obaidat, 2009; Halloun \& Hestenes, 1985). While different factors may cause these misconceptions, forming a mental structure that will be associated with a physics concept is itself complicated in nature. Cognitive science has shown that aggregated experiences from real life form mental images (preconceptions) which always contain contradictory elements and improper structures. The challenge for students comes when they try to tailor existing mental structures to similar concepts of physics that they are being taught in a physics course.

Success in building a bridge between pre-existing mental images and newly-learned physics concepts requires both effective instruction and plausible interventions. At Tufts University, physics education researchers posited that coherent conceptual frameworks do not always result from traditional instruction. Students need to engage effectively in constructing cognitive images (qualitative models) that help them to discriminate between and associate different concepts (McDermott, 1997).

In this paper, the researcher suggests a five stage instructional model. The effectiveness of this model will be determined by first assessing students' levels of comprehension of four light-wave concepts (wavelength, amplitude, frequency, and intensity) as a result of prior teaching, then analyzing their conceptual progression at different stages of the model based on students' abilities to discuss the concepts coherently.

\section{Research Presentation}

The intervention encompassed the principles of Problem-Based Learning (PBL) using a five stage model presented as a computer based tutorial (Fig. 1). A challenge scenario was posed illustrating four wave properties: wavelength, amplitude, intensity, and frequency. In the first stage, the challenge scenario raised three questions defining concepts, articulating correlations, and suggesting solutions. In the second stage, the students navigated to an "initial thoughts" page where they recorded their responses to the challenge questions. The third stage involved accessing an interactive simulation and documents located in the resources section.After accessing these resources, the students started the fourth stage by navigating to the" revised thoughts" section. They considered the initial challenge questions again ,but this time with the benefit of having viewed the resources .The fifth stage, "group thoughts," provided an opportunity for group discussion and learning (Fig. 2) .The five stage model was constructed in an interactive flash platform as standalone executable. The students were able to navigate from stage to stage accordingly, and their performance at each stage was reported electronically and sent to the researcher's email account. 


\section{Research Sample}

The sample selection was a convenience method base consisting of nine students at Hillsboro High School in Nashville, Tennessee (in The US). The students had just finished studying a unit about wave characteristics and speed and were preparing for an exam about this unit.

\section{Data Analysis}

The data obtained were analyzed using the following classifications: scientifically complete answer, incomplete scientific answer, and non-scientific answer. The classifications used to code the responses are shown in Figure 3.

\section{Theoretical Background}

Concepts are "clusters of events, dates, names, objects, and places that share defining attributes" (McCleery and Tindal, 1999). When studying a concept, students need to understand all the characteristics that define the concept and differentiate it from other similar concepts. Students should be able to give relevant examples and identify those that are not relevant. In physics, there is a wide range of concepts that share certain attributes and demand more instructional attention to solidify the assimilation of their understanding. Presmeg (1997) proposed that similarities and differences between concepts are reflecting the ground and tension of a metaphor construction. For example, for the concepts of "pressure" and "force," the ground of a metaphor comes from the idea that pressure is a force and they are both perceived as a sort of interaction between two bodies. The metaphorical tension arises from bounding force associated with pressure in area.

The importance of considering similarities and differences between concepts has focused educators' interest on students' conceptualization processes. Carter, Wilbanks, and Reese (2009) pointed out that observations and experience play a large role in concept construction for most children. For example, observations and experience lead students to perceive heat as a substance; however, physics experts define heat as a process. The discrepancy between what is derived from experience and what is learned from science constitutes a metaphorical picture that is grounded on analogies from what is seen but not fully understood with physics epistemology. In respect to this, Dunlap's study (2007) focused on students' metaphors in constructing a mathematical concept, finding that conceptualization could be a product of metaphorical reasoning influenced by making sense of encountered mathematical information.

As concepts of physics are encountered, teachers should not assume that students will construct the proper mental framework to assimilate them without being carefully instructed. Carter et al. (2009) stressed that the instruction plan for conceptual depiction should involve four instructional stages: modeling information, guiding metaphorical acquisition, providing situations for conceptual implementations and practices, and monitoring progress.

Modeling information to reflect an associated concept should take place in a context that encourages students to be deliberate in their thinking. Problem-Based Learning (PBL) is a strategy that uses challenging scenarios to help students achieve deep levels of understanding of the relevant knowledge to work through the problem, and accordingly to probe for concise acquisition of scientific concepts. In their study to detect the influence of PBL on students' conceptualizations, Akinoglu and Tandogan (2006) found that the application of a problem-based active learning model affects students' conceptual development in a positive way and keeps their misconceptions to a minimum.

Students may work in small learning teams in which productive discussion aids the collection and integration of information about a concept. Jan (2007) looked at students' construction of knowledge about science through oral and written activities performed in a collaborative learning group. The study revealed that cooperative learning fostered by oral and written activities facilitated students' understandings of scientific concepts and helped them to generate explanations.

Scientific concepts are associated with attributes, and scientific metaphors should be guided to frame ties and set clusters. As students assimilate configurations to construct a conceptual metaphor, they need to relate what they are learning to actual implementations and practices. PBL fosters students' ability to identify the salient information in a scenario and to organize that information in a meaningful conceptual framework. PBL highlights interconnections to master concepts in the context in which associated attributes are retained, ensuring that the concepts are grasped and applied appropriately (Albanese \& Mitchell,1993)

\section{Results and Discussion}

The results will be illustrated by capturing and comparing students' initial and revised responses to the posted questions across the module stages. To observe the growth between initial and revised responses, it is important to consider the degree of change between them. The responses to the first question are presented in Table 1 . The table 
shows that some students clearly articulated an insight to overcome the encountered situation. However, several students had misguided views or no views at all. The comparison of initial and revised thoughts does not highlight any change in the degree to which the students reacted to the first question. This could mean that the resource perspective and group discussion stages might not have enough of a significant influence to be incorporated into the students' revised thoughts. Schwartz and Bransford (1998) contend that learning is shown to occur when there is a disparity between initial and revised thoughts. Though no growth was determined in this situation, the revised thoughts seem to be characterized by insightful statements.

Table 2 shows students' initial and revised responses to the second question, which gauged students' understanding of four fundamental light-wave concepts. Students' initial responses regarding their understanding of the wavelength concept fall equally into the three categories. Three students' responses come under the category of "complete scientific answer." These answers clearly defined wavelength as "the distance from crest to crest or trough to trough;" nonetheless, zero crossings on the x-axis were not mentioned. Three responses fall into the category of "incomplete-scientific answer", defining wavelength as "a distance between waves", but with no further explanation. Finally, three responses are coded as "non-scientific answers", incorporating different words and other light-wave concepts in a non-rational manner.

Looking at students' revised responses regarding the concept of wavelength reveals the following:

1) After Resources Confrontation: The "complete scientific answer" category increased by one response, while the "incomplete scientific answer" category gained two more responses. As a result, there were no longer any responses in the category of "non-scientific answer".

2) After Group Discussion: At this final stage, the students' answers showed a noticeable transition to the "scientific answer" category. All students' responses eventually made it to the "scientific answer" category, indicating that the group discussion may have helped to foster the students' overall understanding of the wavelength concept. This result corresponds with Hinde and Kovac's study (2001), which found that, although students who participated in classes that were completely cooperative learning-based performed at the same level as those who participated in classes with marginal cooperative learning, both groups believed that such active learning activities aided comprehension.

The concept of "intensity" returned interesting results in both the students' initial and revised responses. The initial responses showed that, besides the two responses categorized as "non-scientific answers", the rest of the responses would fall into the category of "incomplete scientific answers". In this category, the students seemed to view intensity as a form of energy or speed. Likewise, all responses that were revised after the two interventions (resource confirmation and group discussion) can be classified as "incomplete scientific answers". These revised responses showed that the students used "speed" and "energy" interchangeably to define intensity. It is evident that, at this point, the students had a misconception about light intensity. They saw it as a measure of the amount of energy transferred, or, conversely, as the number of waves passed in a second. They failed to integrate the two addressed arguments to visualize intensity as the rate at which this energy is transferred. That is to say, "the faster the wave travels, the more quickly it transmits energy".

The initial responses showed that the students also maintained a misconception about "amplitude". Four responses were "non-scientific answers", three were "incomplete scientific answers", and two were "complete scientific answers". After the resource intervention, the students' revised their responses as follows: only one response was "non-scientific", five responses were "incomplete scientific answers", and three were "complete scientific answers". It is worth noting that the revised responses shifted from the "non-scientific answer" category to the other two categories. The resources were therefore helpful in reconstructing the students' image of the concept of "amplitude"; however, this image may not depict all the associated attributions of amplitude. But the resource confrontation did allow the students to either support their initial thoughts or to construct some new thoughts.

The students' responses changed slightly after the group discussion, clustering with four responses in the "incomplete scientific" category and five responses in the "complete scientific" category. The ultimate result of this intervention was that the "complete scientific answer" category increased from two responses to five. It is clear that when students talked with each other, they could reformulate their thoughts to include other perspectives from their peers, and they all eventually reached an improved understanding. This result falls in line with Cohen's study (1994), which found that small group learning can be productive for conceptual learning if certain conditions are fulfilled.

The concept of "frequency" was the last wave concept to be investigated. The initial responses were classified by three "non-scientific" responses, five "incomplete scientific" responses, and only one "complete scientific answer". The students' responses after consulting the resources shifted by only one response from the "non-scientific answer" 
category to the "complete scientific answer" category. The "incomplete scientific answer" category remained constant. After group discussion, the students' responses left the "non-scientific" category with a null response; conversely, both the "incomplete scientific answer" and "complete scientific answer" categories were increased by one response each.

Many of the students' responses tended to cluster in the "incomplete scientific answer" category across different stages of the intervention. These responses imply that the students lacked the skills to express their understanding of the concept of "frequency" using correct language. Many of the students might have had an appropriate understanding of frequency; however, they associated the word "period" with a boundary within a wave itself. (The word "period" as a physics concept distinctly differs from frequency, yet they are related). Presumably, the students were confused by these two concepts or were using the word "period" interchangeably with the word "time". Enghag, Gustafsson and Jonsson (2007) found that students reach consensus in group discussions using exploratory talk, a kind of talk that includes hesitations and changes of directions, assertions and questions, self-monitoring and reflexivity. Thus, with respect to the previous results, it may be contended that individual misunderstandings or improper representations may occur during the conversations and thus be held by the rest of the group, unless other group members indicate their opposition.

Table 3 shows the students' initial and revised responses to possible correlations between the four terms: wavelength, intensity, amplitude, and frequency. Overall, the responses did not articulate all possible correlations between the four concepts. The initial responses revealed that the majority of the students (six) could not correctly pinpoint a possible correlation between the four wave-light concepts, yet three responses did correctly find one or two correlations.

The revised responses show that all of the students were able to find at least one correlation between the four concepts. Though this would appear to reflect some improvement, the students could not figure out all the possible correlations. After the resource consultation, which included an interactive demonstration of the four concepts, all the students found at least one correct correlation (mainly, the one between wavelength and frequency); one student alluded to a possible correlation between amplitude and intensity; and another student positively identified this correlation. Similarly, students' responses showed a slight improvement after the group discussion, with five responses articulating one correct correlation and four responses with two correct correlations. It is noticeable that all responses with two correct correlations related to "wavelength and frequency" and "intensity and amplitude". Surprisingly, no attempts were made to make other correlations across the four concepts. It could be said that the revised responses corroborate claims that discussion can dramatically facilitate student learning (Mazur, 1997). However, the data also illustrate that what the students have to discuss is significant, with the simulation leading to even more fruitful discussions.

\section{Conclusion}

Researchers have noted the success of the How People Learn (HPL) framework and STAR Legacy Cycle in bioengineering education (Roselli, \& Brophy, 2003), teacher education (PT3 Group at Vanderbilt, 2003), and corporate training (Vye, Burgess, Bransford, \& Cigarron, 2002). Accordingly, some of the results of this study (answers to the second and third questions about the four concepts of light waves and their correlations) align with these previous studies and indicate that the five-stage cycle for teaching physics using a computer-based tutorial situates and facilitates student learning in physics. Within the context of the five-stage cycle, the students can improve their initial responses and transfer new insights thoroughly as they access the resources and discuss in small groups.

However, the other results from this study (the answers to the first question about the challenging scenario) indicate that students' problem-solving skills are not challenged by the five-stage model. The students demonstrated improvement in learning the four physics concepts and some of their correlations, but most of the students could not construct a useful knowledge structure to overcome the challenging scenario they encountered.

In summary, learning physics is more than just coming to understand the concepts of physics. It also entails learning how to think like a physicist: developing the habits of mind that allow one to make productive use of knowledge (R.J. Dufresne et al., 2000). Therefore, the role of the teacher never diminishes; thus, it is fundamental to look at how to integrate the role of the teacher into this intervention to engineer learning experiences and guide students' learning efforts, while students strive to become active, self-monitoring constructors of knowledge.

\section{References}

Akinoglu, O., \& Tandogan, R. (2007). The effects of problem-based active learning in science education on students' academic achievement, attitude and concept learning. Eurasia Journal of Mathematics, Science and 
Technology Education, 3(1), 71-81

Albanese, M., \& Mitchell, S. (1993). Problem-based learning: A review of the literature on its outcomes and implementation issues. Academic Medicine, 68(1), 52-81. doi:10.1097/00001888-199301000-00012, http://dx.doi.org/10.1097/00001888-199301000-00012. PMid:8447896

Barnes, D., \& Todd, F. (1995). Communication and learning revisited. Portsmouth: Boynton/Cook Publishers.

Boud, D., \& Feletti, G. (1997). The challenge of problem-based learning (2nd ed.). London: Kogan Page.

Cohen, E. G. (1994). Restructuring the classroom: Conditions for productive small groups. Review of Educational Research, 64(1), 1-35

Dufresne, R., Gerace, W., Mestre, J., \& Leonard, W. (2000). ASK-IT/A2L: Assessing student knowledge with instructional technology. (Technical report no. UMPER G-2000-09). Amherst: University of Massachusetts Physics Education Research Group.

Enghag, M., Gustafsson, P., \& Jonsson, G. (2007). From everyday life experiences to physics understanding occurring in small group work with context rich problems during introductory physics work at university. Research Science Education, 37, 449-467. doi:10.1007/s11165-006-9035-4, http://dx.doi.org/10.1007/s11165-006-9035-4

Halloun, I., \& Hestenes, D. (1985). The initial knowledge state of college physics students. American Journal of Physics, 53, 1043-1055. doi:10.1119/1.14030, http://dx.doi.org/10.1119/1.14030

Hammer D. (1994). Epistemological beliefs in introductory physics. Cognition and Instruction, 12(2), 151-183. doi:10.1207/s1532690xci1202_4, http://dx.doi.org/10.1207/s1532690xci1202_4

Hinde, R., \& Kovac, J. (2001). Student active learning methods in physical chemistry. Journal of Chemical Education, 78(1), 93-99. doi:10.1021/ed078p93, http://dx.doi.org/10.1021/ed078p93

Malkawi, E., \& Obaidat, I. (2009). The grasp of physics concepts of motion: Identifying particular patterns in students' [Online] Available: http://academics.georgiasouthern.edu/ijsotl/v3n1/articles/PDFs/Article_ObaidatMalkawi.pdf

May, D., \& Etkina, E. (2002). College students' epistemological self-reflection and its relationship to conceptual learning. American Journal of Physics, 70(12), 1249-1258. doi:10.1119/1.1503377, http://dx.doi.org/10.1119/1.1503377

Mazur, E. (1997). Peer instruction. Upper Saddle, NJ: Prentice Hall.

McDermott, L. (1997). How research can guide us in improving the introductory course. In J. Wilson (Ed). Proceedings of the Conference on Introductory Physics Course (pp 33-45). New York: Wiley.

PT3 Group at Vanderbilt. (2003). Three amigos: Using anchored modular inquiry to help prepare future teachers. Educational Technology Research and Development, 51(1), 105-123. doi:10.1007/BF02504521, http://dx.doi.org/10.1007/BF02504521

Redish, E., Saul, J., \& Steinberg, R. (1998). Students' expectations in introductory physics. American Journal of Physics, 66, 212-224. doi:10.1119/1.18847, http://dx.doi.org/10.1119/1.18847

Roselli, R., \& Brophy, S. (2003). Redesigning a biomechanics course using challenge based instruction. IEEE Engineering in Medicine and Biology Magazine, 22(4), 66-70. doi:10.1109/MEMB.2003.1237504, http://dx.doi.org/10.1109/MEMB.2003.1237504. PMid:14515695

Jang, S. (2007). A study of students' construction of science knowledge: Talk and writing in a collaborative group.

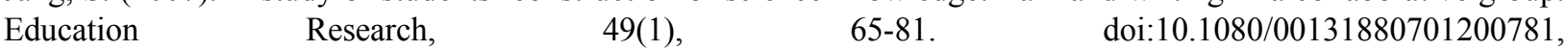
http://dx.doi.org/10.1080/00131880701200781

Şahin, C., Ipek, H., \& Ayas, A. (2008). Students' understanding of light concepts primary school: A cross-age study. Asia-Pacific Forum on Science Learning and Teaching, 9(1), 1-19

Vye, N. (2002). Using Computer-Assisted Case-Based Instruction in Corporate Training. In P. Barker \& S. Rebelsky (Eds.), Proceedings of World Conference on Educational Multimedia, Hypermedia and Telecommunications 2002 (pp. 1997-2000). Chesapeake, VA: AACE 
Table 1. Students' responses to the challenging scenario

\begin{tabular}{cccc}
\hline & Non-scientific & $\begin{array}{c}\text { Incomplete } \\
\text { scientific }\end{array}$ & $\begin{array}{c}\text { Complete } \\
\text { scientific }\end{array}$ \\
\hline Initial & 5 & 1 & 3 \\
$\begin{array}{c}\text { After resources } \\
\text { confrontation }\end{array}$ & 5 & 1 & 3 \\
$\begin{array}{c}\text { After group } \\
\text { discussion }\end{array}$ & 5 & 1 & 3 \\
\hline
\end{tabular}

Table 2. Students' perspectives on wavelength, intensity, amplitude, and frequency

\begin{tabular}{|c|c|c|c|c|}
\hline & & Non-scientific & $\begin{array}{l}\text { Incomplete } \\
\text { scientific }\end{array}$ & $\begin{array}{l}\text { Complete } \\
\text { scientific }\end{array}$ \\
\hline \multicolumn{5}{|l|}{ Wavelength } \\
\hline & Initial & 3 & 3 & 3 \\
\hline & $\begin{array}{c}\text { After resources } \\
\text { confrontation }\end{array}$ & 0 & 5 & 4 \\
\hline & $\begin{array}{l}\text { After group } \\
\text { discussion }\end{array}$ & 0 & 0 & 9 \\
\hline \multicolumn{5}{|l|}{ Intensity } \\
\hline & Initial & 2 & 7 & 0 \\
\hline & $\begin{array}{c}\text { After resources } \\
\text { confrontation }\end{array}$ & 0 & 9 & 0 \\
\hline & $\begin{array}{l}\text { After group } \\
\text { discussion }\end{array}$ & 0 & 9 & 0 \\
\hline \multicolumn{5}{|l|}{ Amplitude } \\
\hline & Initial & 4 & 3 & 2 \\
\hline & $\begin{array}{c}\text { After resources } \\
\text { confrontation }\end{array}$ & 1 & 5 & 3 \\
\hline & $\begin{array}{l}\text { After group } \\
\text { discussion }\end{array}$ & 0 & 4 & 5 \\
\hline \multicolumn{5}{|l|}{ Frequency } \\
\hline & Initial & 3 & 5 & 1 \\
\hline & $\begin{array}{c}\text { After resources } \\
\text { confrontation }\end{array}$ & 2 & 5 & 2 \\
\hline & $\begin{array}{l}\text { After group } \\
\text { discussion }\end{array}$ & 0 & 6 & 3 \\
\hline
\end{tabular}


Table 3. Students' responses on possible correlations between the four concepts

\begin{tabular}{|c|c|c|c|c|}
\hline & No Correlations & One Correlation & $\begin{array}{c}\text { Two } \\
\text { Correlations }\end{array}$ & $\begin{array}{c}\text { Three } \\
\text { correlations and } \\
\text { more }\end{array}$ \\
\hline Initial & 6 & 2 & 1 & 0 \\
\hline $\begin{array}{l}\text { After resources } \\
\text { confrontation }\end{array}$ & 0 & 7 & 2 & 0 \\
\hline $\begin{array}{l}\text { After group } \\
\text { discussion }\end{array}$ & 0 & 5 & 4 & 0 \\
\hline
\end{tabular}

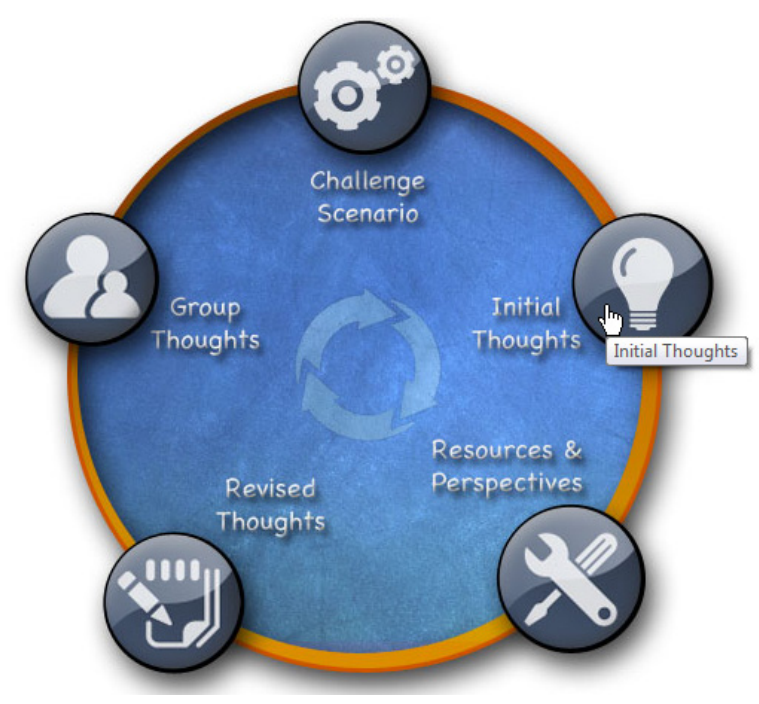

Figure 1. Five Stage Cycle Model 

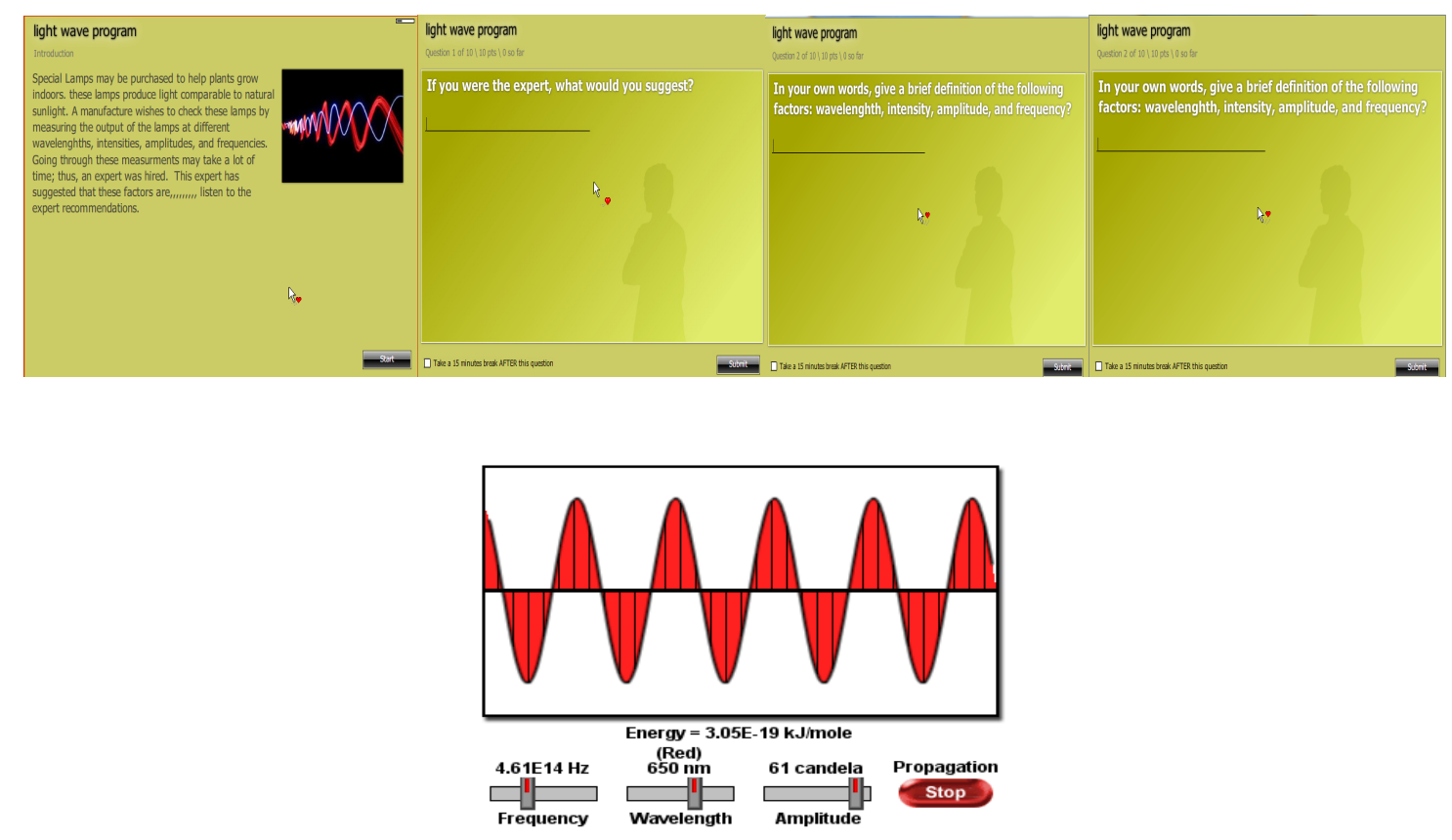

Figure 2. Five Stage Model Layouts

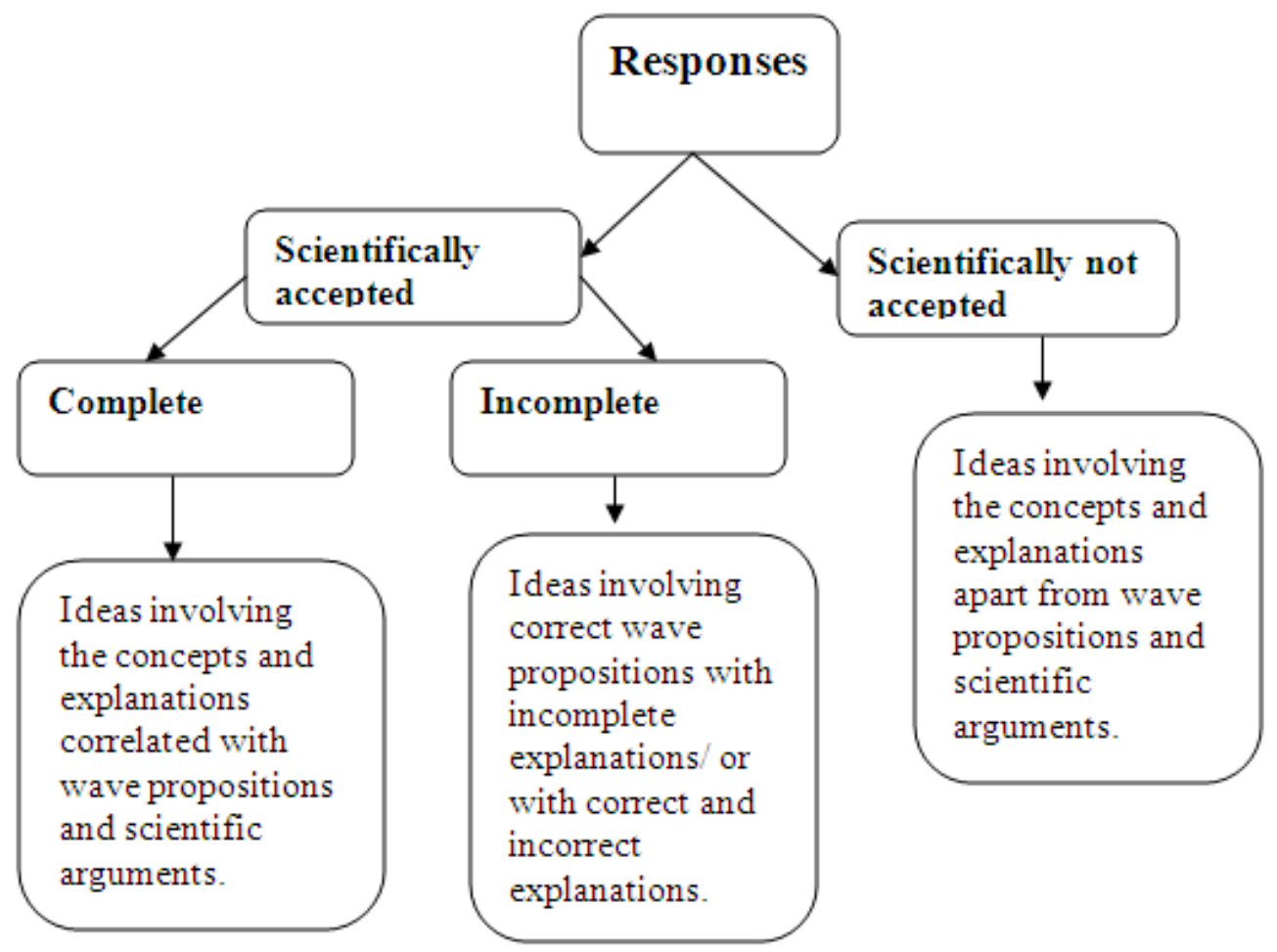

Figure 3. Response coding criteria. 


\section{Appendix A}

Scope of students' responses on the challenging scenario

Initial thoughts
Revised thoughts ( resource confrontation)
Revised thoughts ( group

discussion)
Measure the sunlight and compare it to the output of the lamp.
Test the plants under different lamps and various combinations of light features, and manufacture a lamp accordingly.

Examine the light.

To look at the wavelength and frequency the light wave gives off in order to learn more about the light wave you are observing.

To create lights which would mimic the characteristics of UV rays from the sun. These lights would then be tested on different types of plants.

Test different intensities on the same kind of plants.

To run at the speed of light.

Do continuous testing with different frequencies, amplitudes, wavelengths, and intensities.

Test the light on different plants.

All features are in a wave so it has the same output.
Same as before

To look at the wavelength and frequency the light wave (the manufactured lamp) gives off, and to learn more about the light wave of sunlight.

Same as before, and to collect information on the wavelength and frequency which would connect to the intensity of the sunlight.

Same as before

Same as before

Do testing on lamps with different frequencies to meet the one matching to sunlight.
Same as before

Same as before

\section{Same as before}

Same as before

Same as before

Same as before

Same as before

Same as before

Same as before

Same as before

Same as before 


\section{Appendix B}

Scope of students' responses on the definitions of the four concepts

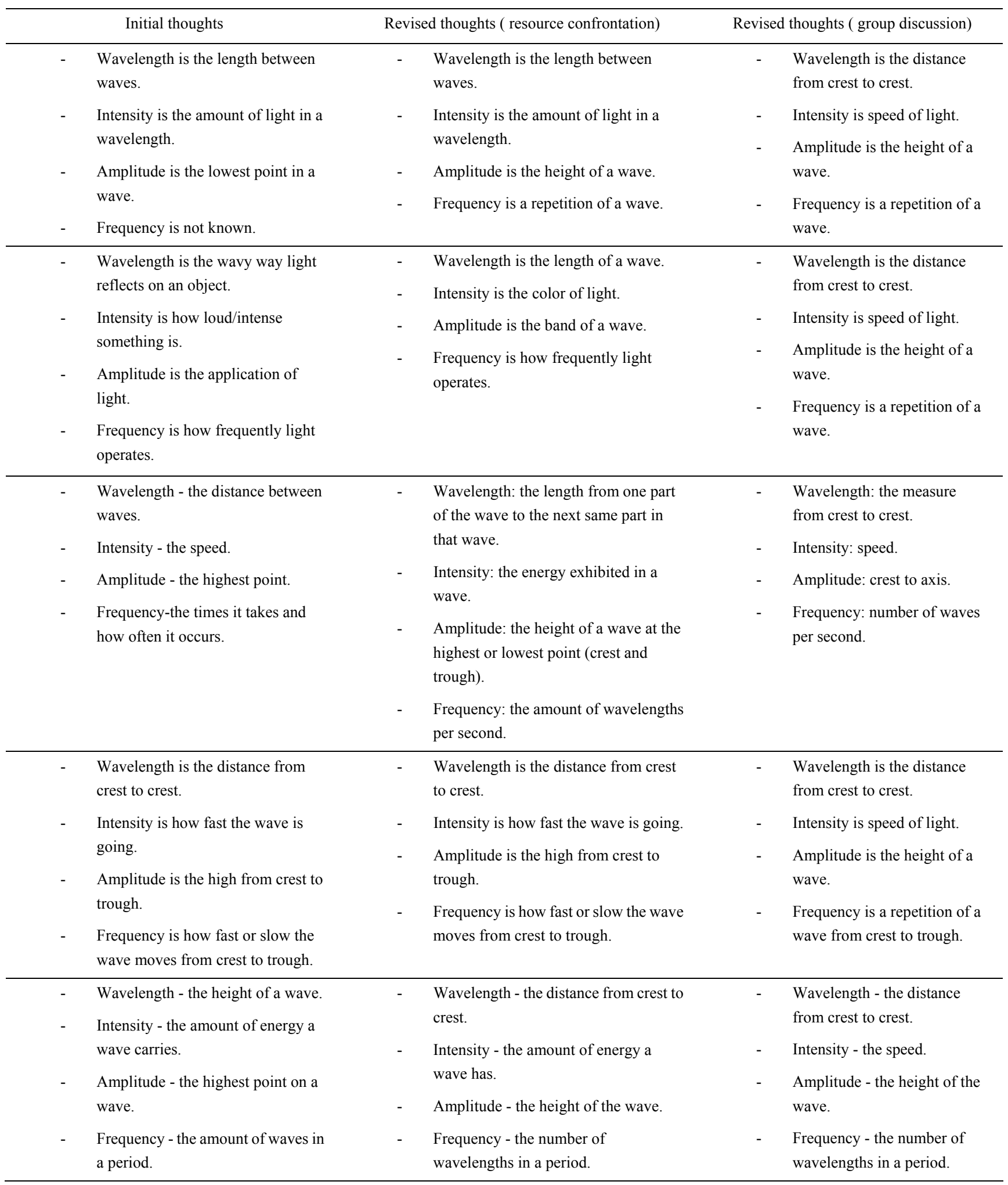


- Wavelength is the measure from trough to trough or crest to crest.

- $\quad$ Amplitude: the measure from crest to the lowest point.

- $\quad$ Frequency: the number of waves in a certain period.

- Intensity: the amount of energy a wave can carry.

- Wavelength is the length of the wave.

- Intensity describes how intense it is.

- $\quad$ Amplitude is a measure of the number of amps.

- $\quad$ Frequency is how frequently the wave occurs.
- Wavelength: the measure from the crest to the lowest point on where it would cross the $\mathrm{x}$-axis.

- Amplitude: crest to axis.

- $\quad$ Frequency: the number of waves in a certain period.

- Intensity is the amount of energy a wave carries.

- Wavelength is the length of wave.

- Intensity is how intense it is reflected in color.

- Amplitude is how big the wave is.

- $\quad$ Frequency is how often it occurs.

- Wavelength: the measure from crest to crest.

- Intensity: speed.

- $\quad$ Amplitude: crest to axis.

- $\quad$ Frequency: number of waves in a period.

- Wavelength is the length between two crests or troughs.

- Intensity is the human perceiving a wave color.

- $\quad$ Amplitude is the magnitude of the wave.

- $\quad$ Frequency is the amount of waves.

- Wavelength is the length between wave crests.

- $\quad$ Intensity is the human perceiving loudness of a wave color.

- $\quad$ Amplitude is the magnitude of the wave.

- $\quad$ Frequency is the amount of waves per second.
- Wavelength is the length between two crests or troughs.

- Intensity is the human perceiving loudness of a wave color.

- $\quad$ Amplitude is the magnitude of the wave.

- $\quad$ Frequency is the amount of waves each second.

- Wavelength is the length between two crests or troughs.

- Intensity is human perception of wave color.

- $\quad$ Amplitude is the magnitude of the wave.

- $\quad$ Frequency is how many waves it has per second. 


\section{Appendix C}

Students' responses on possible correlations between the four concepts

\begin{tabular}{|c|c|c|}
\hline Initial thoughts & $\begin{array}{l}\text { Revised thoughts ( resource } \\
\text { confrontation) }\end{array}$ & Revised thoughts ( group discussion) \\
\hline $\begin{array}{l}\text { Negatively wavelength and amplitude } \\
\text { are tide. }\end{array}$ & $\begin{array}{l}\text { Wavelength and frequency tide } \\
\text { negatively. }\end{array}$ & $\begin{array}{l}\text { they are all correlated in a negative } \\
\text { way. }\end{array}$ \\
\hline $\begin{array}{l}\text { All these have specific light feature so } \\
\text { they are not correlated. }\end{array}$ & $\begin{array}{l}\text { Frequency and wavelength correlate } \\
\text { negatively. }\end{array}$ & $\begin{array}{l}\text { they are all correlated in a negative } \\
\text { way. }\end{array}$ \\
\hline Not sure. & $\begin{array}{l}\text { Wavelength can be used for light in } \\
\text { order to figure out frequency. Intensity } \\
\text { is measured by a combination of } \\
\text { amplitude and frequency. They are } \\
\text { correlated somewhat. }\end{array}$ & $\begin{array}{l}\text { Wavelength and frequency are inversely } \\
\text { correlated. Intensity and frequency are } \\
\text { correlated in a positive way. }\end{array}$ \\
\hline $\begin{array}{l}\text { Wavelength and frequency are } \\
\text { negatively correlated because the } \\
\text { frequency and the wavelength are } \\
\text { inversely proportional. }\end{array}$ & $\begin{array}{l}\text { Wavelength and frequency are } \\
\text { negatively correlated. } \\
\text { Amplitude does not affect frequency, } \\
\text { wavelength or energy. }\end{array}$ & $\begin{array}{l}\text { Wavelength and frequency are } \\
\text { negatively correlated. }\end{array}$ \\
\hline $\begin{array}{l}\text { All these factors are a measurement of } \\
\text { some part of the wave to say that they } \\
\text { are correlated }\end{array}$ & $\begin{array}{l}\text { The frequency and wavelength are } \\
\text { inversely proportional. }\end{array}$ & $\begin{array}{l}\text { The frequency and wavelength are } \\
\text { inversely proportional while intensity } \\
\text { and frequency are positively correlated. }\end{array}$ \\
\hline $\begin{array}{l}\text { Frequency and intensity, and } \\
\text { wavelength and frequency are } \\
\text { correlated in the fact that if one is } \\
\text { down, so is the other one. }\end{array}$ & $\begin{array}{l}\text { Frequency and wavelength are } \\
\text { correlated negatively. }\end{array}$ & $\begin{array}{l}\text { Frequency and wavelength are } \\
\text { correlated inversely. }\end{array}$ \\
\hline $\begin{array}{l}\text { Wavelength correlates with frequency } \\
\text { and wave speed, intensity correlates } \\
\text { positively with amplitude. }\end{array}$ & $\begin{array}{l}\text { Wavelength correlates negatively with } \\
\text { frequency, while amplitude and } \\
\text { intensity do not correlate. }\end{array}$ & $\begin{array}{l}\text { Wavelength and frequency correlate } \\
\text { negatively, while amplitude and } \\
\text { intensity do not correlate. }\end{array}$ \\
\hline $\begin{array}{l}\text { Frequency and wavelength correlate } \\
\text { negatively because when frequency } \\
\text { goes up, wavelength goes down. } \\
\text { Amplitude and intensity correlate } \\
\text { positively because a higher amplitude } \\
\text { means more intensity. }\end{array}$ & $\begin{array}{l}\text { Wavelength and frequency are } \\
\text { negatively correlated. Amplitude and } \\
\text { intensity are positively correlated. }\end{array}$ & $\begin{array}{l}\text { Wavelength and frequency are } \\
\text { negatively correlated. Intensity and } \\
\text { amplitude are positively correlated. }\end{array}$ \\
\hline $\begin{array}{l}\text { They are all correlated because they } \\
\text { all pertain to the amount and level of } \\
\text { light produced. }\end{array}$ & $\begin{array}{l}\text { Frequency increases as wavelength } \\
\text { decreases. }\end{array}$ & $\begin{array}{l}\text { Wavelength and frequency are } \\
\text { negatively correlated. Intensity and } \\
\text { amplitude are positively correlated }\end{array}$ \\
\hline
\end{tabular}

